\title{
Development and Implementation of Calibration Mathematical Models and Procedures for Precise Digital Level
}

\author{
Ashraf A. A. Beshr, Ehigiator-Irughe Raphael
}

\section{ABSTRACT}

\begin{abstract}
Achieving the desired results and safety for any engineering project requires regularly review and check the technical specifications and accuracy of the geodetic instruments. Standard calibration models and procedures are exist for all geodetic instruments but it must be developed and modified to meet the standard for advanced precise digital level especially for deformation measurements. Digital levels are widely used for setting out engineering structures and monitoring the structural deformation because of their accuracy, in addition to the possibility of automatically collecting and storing data, which save time and effort required for observations. When performing measurements for an industrial building or construction site, due to the operation of various mechanisms and equipment, vibration occurs on the surface of the earth or on the concrete base, on which a tripod with a digital level is mounted. Under these conditions, the frequency and amplitude of the oscillations has a great effect on the observations of modern digital geodetic instruments. This paper investigates the accuracy of precise digital level observations (height differences and distances) for two cases which are: observations in laboratory and observations in the field (open area - outdoors observations with sun light and different weather condition than laboratory). The paper presents also two new suggested observations techniques for determining the collimation error (angle $(\theta)$ ) of precise levels depending on least square theory which in turn provide a significant improvement of the suggested methods for determining the characteristic of digital levels. The research presents also experimentally the results of investigating the effect of (level tripod) vibration on the digital level observations accuracy and suggest a practical technique to reduce the influence of the tripod-level vibration system on the resulted observations.
\end{abstract}

Keywords: Accuracy, digital levels, collimation error, vibration, digital levels, calibration.

\section{INTRODUCTION}

There are widely used instruments in applied surveying and geodesy that allow precise measurements such as digital levels, digital theodolites, total stations, laser scanners ... etc. These instruments must be tested and calibrated regularly to investigate its technical characteristics, which in turn will improve the accuracy of its observations. Digital levels are modern digital multifunctional geodetic instruments combining the functions of a high-precision optical level with electronic storage device and built-in software for measuring reduced levels of any point using fully automated tools and methods [2], [4]. Digital level was designed to work at any conditions where fast and accurate height measurements are necessary such as setting the required slopes and longitudinal profiles, structural deformation monitoring and creating a high-altitude justification of reference geodetic networks [3].

The principle of digital level work is achieved by using of a pattern recognition imaging system built into the instrument
Published Online: August 19, 2020

ISSN: $2684-446 \mathrm{X}$

DOI : $10.24018 /$ ejgeo.2020.1.4.50

Ashraf A. A. Beshr*

Mansoura University, Egypt.

(e-mail: aaabeshr@mans.edu.eg)

Ehigiator-Irughe Raphael

University of Benin, Nigeria.

(e-mail: raphael.ehigiator@uniben.edu)

*Corresponding Author and level staff (level rod) graduated with a specified bar code. The observer directs the level at one of the special bar code rods, and presses a button to take the observations. An image of the barcode rod is received at the level and is correlated to an internal digital image of the rod [4], [7]. The internal software inside level determines actually the position where the level line of sight is intercepting the bar code rod [7].

The digital leveling contains many sources of errors which affect the accuracy of the resulting observations. Therefore, the technical properties of digital levels must be investigated, and new calibration methods are required also to improve the accuracy of its observations to achieve the requirements of any engineering project especially for the projects which require high accuracy such as structure deformation monitoring [6]. Level Collimation error test is experimental work to determine and identify the error value present in level. Several methods are known for determining and correcting the angle $(\theta)$ for levels in the field [7], [14]. The collimation error or angle $(\theta)$ of the level is determined in field or laboratory conditions by using simplified test named 
two pegs test in its simple form, in which the excess between two points fixed on the ground is measured with a calibrated instrument twice, from two stations.

This paper presents two suggested and modified techniques (field work and derived equations) for determining the collimation error (angle $(\theta)$ ) for precise digital levels using least square theory. Experimental work are presented also to validate the applied techniques.

Vibrations and oscillations sometimes appear when carrying out engineering projects such as pile driving, dynamic compaction and operating heavy metal equipment ... etc [8], [9]. Vibrations also appear during the work of turbines which are used to generate electrical energy. These vibrations affect the surrounding buildings, people, and sensitive instruments. Vibrations have a great effect also on the accuracy of geodetic observations, especially the modern geodetic electronic instruments which are very sensitive to the surrounding environment and atmosphere [3], [9], [11]. So, it is important to study the effect of these vibrations on the geodetic observations accuracy and find a practical technique to reduce the influence of these vibrations, and this is one of the purposes of this research.

Monitoring and control of vibrations were studied by a number of researchers [10], [12], [13]. This paper presents experimentally the results of investigating the effect of (level-tripod) vibrations on the accuracy of precise digital level observations and suggest a technical method to reduce its effect on the observations accuracy.

\section{THE ACCURACY OF PRECISE DIGITAL LEVEL OBSERVATIONS}

Two tests were carried out to investigate the accuracy of precise digital level observations. The first test was done in laboratory and the other was done in field (outdoors - open area). The used digital level was Trimble DiNi and its associated bar-code rod (bar code staff). In the two tests, base line was chosen between two fixed points. The line was divided into 6 sections with unequal lengths. The used digital level was fixed at the first station of base line and bar code rod (staff) will be fixed at different distances from the instrument $5.3 \mathrm{~m}, 11.4 \mathrm{~m}, 15.4 \mathrm{~m}, 20.5 \mathrm{~m}, 25.2 \mathrm{~m}$ and 31.1 $\mathrm{m}$. At each bard code position, the bar code reading and horizontal distance from the level to the staff was measured 20 times. The same procedure of practical work was repeated several different times of the day to get the mean values of all observations. The test was carried out in laboratory (indoor observations) and then in outside (field observations) during the daytime under natural light. For each position, the standard deviation of bar code rod (staff) readings was calculated by using formula [5]:

$$
m_{h}=\sqrt{\frac{\sum_{i=1}^{n} v_{i}^{2}}{n-1}}=\sqrt{\frac{\sum_{i=1}^{n}\left(h_{i}-\bar{h}\right)^{2}}{n-1}}
$$

where:

$m_{h}-$ Standard deviation of measured height differences;

$\mathrm{n}$ - Number of observations;

$v_{i}$ - The residual of measurements,

$h_{i}=$ Observations,

$\bar{h}=$ Mean value of observations

The values of standard deviation of bar code rod (staff) readings resulted from precise digital level observations in laboratory and field (open area) are illustrated in Table (1).

TABLE 1: THE STANDARD DEVIATION OF DIGITAL LEVEL OBSERVATIONS IN LABORATORY AND IN THE FIELD

\begin{tabular}{cccccccc}
\multicolumn{6}{c}{ TABLE 1: THE STANDARD DEVIATION OF DIGITAL LEVEL OBSERVATIONS IN LABORATORY AND IN THE FIELD } \\
\hline & $\begin{array}{c}\text { Mean value of measured } \\
\text { horizontal distance, } \mathrm{m}\end{array}$ & 5.3129 & 11.4511 & 15.3672 & 20.4969 & 25.2142 & 31.1353 \\
& $\begin{array}{c}\text { Standard deviations of } \\
\text { In laboratory } \\
\text { rod readings, }\left(m_{h}\right) \mathrm{mm}\end{array}$ & 0.016 & 0.0339 & 0.075 & 0.117 & 0.154 & 0.198 \\
\hline $\begin{array}{c}\text { Field Observations } \\
\text { (Open area) }\end{array}$ & $\begin{array}{c}\text { Mean value of measured } \\
\text { horizontal distance, } \mathrm{m} \\
\text { Standard deviations of } \\
\text { rod readings, }\left(m_{h}\right) \mathrm{mm}\end{array}$ & 0.0199 & 0.0416 & 0.0647 & 0.13286 & 0.1654 & 0.2191 \\
\hline
\end{tabular}

From Table 1, the following items can be deduced:

- When the distance between the precise digital levels and bar-code rod (staff) increase, the standard deviation of staff readings and horizontal distances will increase and consequently the accuracy will decrease.

- The resulting differences between measurement errors resulted from observations in laboratory and in site (outdoors) differs on average by $8-12 \%$. The difference appears due to the difference in weather conditions between the laboratory and outdoors (on site), such as temperature and atmosphere humidity and its effect on electronic devices.

Least square estimation technique was used to establish formula connecting the standard deviation of staff readings $(\mathrm{mh})$ and the horizontal distances (D) resulted from experimental investigation for the two observations conditions cases. The derived equations using least square techniques and its correlation factor are shown in Table 2.
TABLE 2: THE EQUATION OF STANDARD DEVIATION OF DISTANCE RESULTING FROM PRECISE DIGITAL LEVEL OBSERVATIONS USING LEAST SQUARE TECHNIQUES

\begin{tabular}{ccc}
\hline & $\begin{array}{c}\text { The resulting equation between } \\
\text { observations accuracy and } \\
\text { distance, }\left(\text { where D in m and } \mathrm{m}_{\mathrm{h}}\right. \\
\text { in } \mathrm{mm})\end{array}$ & $\begin{array}{c}\text { Correlation } \\
\text { Factor }(\mathrm{R})\end{array}$ \\
\hline $\begin{array}{c}\text { Observations in } \\
\text { laboratory } \\
\begin{array}{c}\text { Observations } \\
\text { outside (on site) }\end{array}\end{array}$ & $\mathrm{m}_{\mathrm{h}}=0.006 \mathrm{D}-0.012$ & 0.9864 \\
\hline
\end{tabular}

\section{PROPOSED COLLIMATION ERROR TEST}

As known, one of the basic essential requirements leveling procedure for any engineering project is that the line of sight must completely coincide with the optical axis of the digital level, which means that the line of collimation must be horizontal and is parallel to the bubble axis when the 
instrument is completely leveled [3], [4]. But if the optical axis of the level is not coinciding with the line of sight and tilts up or down, this means that the collimation line is not parallel with the bubble axis, then the device has a collimation error and can be defined by angle $(\theta)$. This error mainly depends on the distance between the digital level and bar code rod (staff). Therefore, the digital level must be constantly calibrated to ensure that there is no such error, which affects the resulting observations.

This test determines the amount of error and if an error occurs notify the technician (the level must be serviced). When the collimation error is determined and identified, the digital level can be adjusted, or the adjustment can be mathematically applied directly to each bar code staff reading.

In this paper, two suggested modified observations techniques are presented with its derived applied mathematical formula for determining angle $(\theta)$. Field observations using the two suggested modified observations techniques with results analysis are presented as following:

\section{A. The first mathematical model for determining angle $(\theta)$}

In this suggested modified test, two vertical staves are fixed at stations $\mathrm{A}$ and $\mathrm{B}$, then measurements are taken from different level stations (Fig. 1). To obtain the average value of the angle $(\theta)$, the principle of least squares is used as following:

As shown in Fig. 1, the line of sight does not coincide with the bubble axis.

Then, the measured difference between stations A and B

$$
(\Delta \text { hobs. })=\mathrm{rA}-\mathrm{rB}
$$

The actual difference (real difference) between stations A and $\mathrm{B}$

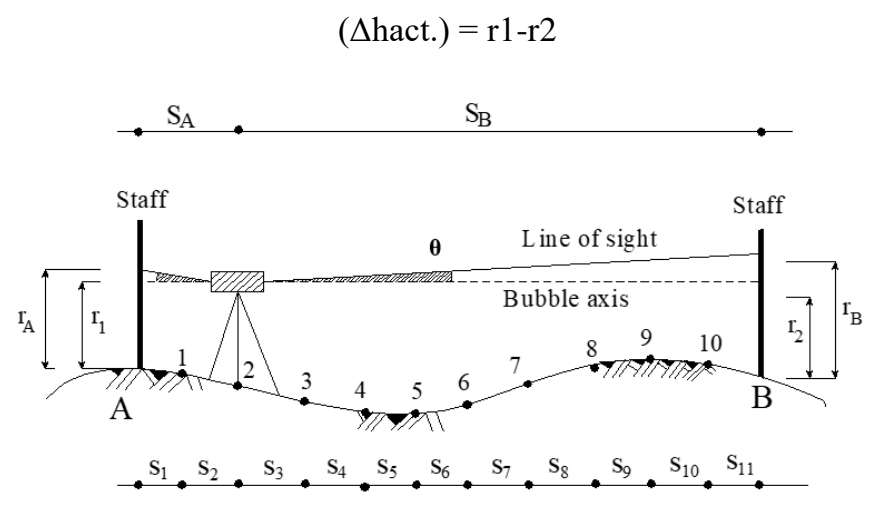

Fig. 1. The first suggested modified observations method for determining angle $(\theta)$ for leveling.

Since the value of angle $(\theta)$ is small, then $\tan (\theta)=\theta$

From the geometry of figure (1), the following formula can be deduced:

$\left\{\begin{array}{l}r_{1}-r_{2}=\left(r_{A}-s_{A} \cdot \theta\right)-\left(r_{B}-s_{B} \cdot \theta\right) \\ =\left(r_{A}-r_{B}\right)-\theta \cdot\left(s_{A}-s_{B}\right.\end{array}\right\}$

For simplify, assume:

$S=S_{A}-S_{B}, \quad \Delta h_{\text {act. }}=r_{1}-r_{2}, \Delta h_{o b s .}=r_{A}-r_{B}$ then we have

$\Delta h_{\text {act. }}=\Delta h_{\text {obs. }}-\theta \cdot S$

Then, the systematic error in observations (V) can be written as:

$$
V=\Delta h_{\text {obs. }}-\left(\Delta h_{\text {act. }}+S . \theta\right)
$$

By using the first principle of least square theory, the term $\sum V^{2}=\sum\left(\Delta h_{o b s}-\left(\Delta h_{a c t}+S \theta\right)\right)^{2}$ must be minimum.

Mathematically, this means that:

$$
\frac{\partial}{\partial \theta} \sum\left(\Delta h_{o b s}-\left(\Delta h_{a c t}+S \theta\right)\right)^{2}=0
$$

By differentiation and simplification, the angle $(\theta)$ will have the form:

$$
\theta^{\prime \prime}=\frac{\sum \Delta h_{o b s} S}{\sum S^{2}} \rho^{\prime \prime}
$$

Formula (2) is the derived formula for calculating the collimation error (angle $\theta$ ) for this suggested modified observation technique. This technique can be applied for both digital and ordinary optical leveling.

\section{$B$. The second mathematical model for determining the angle $(\theta)$}

In this suggested modified test for determining angle $(\theta)$ as shown in figure (2), the digital level was fixed at stations A and $\mathrm{B}$, the staff was moved at points $1 \ldots \mathrm{n}$. The observations (height differences and horizontal distances) were recorded at each staff position. The derived formula for calculating the angle $(\theta)$, for this case, can be summarized as following:

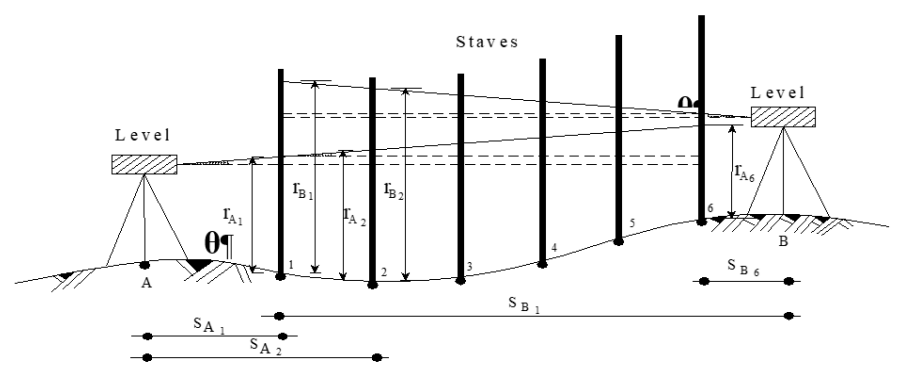

Fig. 2. The second suggested observations method for determining angle $(\theta)$ for leveling.

As shown in Fig. (2), the line of sight does not coincide with the bubble axis. Since the value of angle $(\theta)$ is small, then:

$$
\tan (\theta)=\theta
$$

Then, from geometry of figure (2), it is found that:

$$
\left(r_{A_{1}}-s_{A_{1}} \cdot \theta\right)-\left(r_{A_{2}}-s_{A_{2}} \cdot \theta\right)=\left(r_{B_{1}}-s_{B_{1}} \cdot \theta\right)-\left(r_{B_{2}}-\right.
$$

This equation can be rearranged to have the form:

$$
\left(r_{A_{1}}-r_{A_{2}}\right)-\theta \cdot\left(s_{A_{1}}-s_{A_{2}}\right)=\left(r_{B_{1}}-r_{B_{2}}\right)-\theta \cdot\left(s_{B_{1}}-s_{B_{2}}\right)
$$


Then, the systematic error in observations (V) can be written as:

$\left\{\begin{array}{l}V=\left(r_{A_{1}}-r_{A_{2}}\right)-\theta \cdot\left(s_{A_{1}}-s_{A_{2}}\right)-\left(r_{B_{1}}-r_{B_{2}}\right)+\theta \cdot\left(s_{B_{1}}-s_{B_{2}}\right) \\ V=\left[\left(r_{A_{1}}-r_{A_{2}}\right)-\left(r_{B_{1}}-r_{B_{2}}\right)\right]-\theta \cdot\left[\left(s_{A_{1}}-s_{A_{2}}\right)-\left(s_{B_{1}}-s_{B_{2}}\right)\right]\end{array}\right\}(8)$

By using the first principle of least square theory; the term $\sum V^{2}$ must be minimum.

So:

$$
\begin{aligned}
& \sum V^{2}=\sum\left(\left[\left(r_{A_{1}}-r_{A_{2}}\right)-\left(r_{B_{1}}-r_{B_{2}}\right)\right]-\theta \cdot\left[\left(s_{A_{1}}-s_{A_{2}}\right)-\right.\right. \\
& \left.\left.\left(s_{B_{1}}-s_{B_{2}}\right)\right]\right)^{2}
\end{aligned}
$$

For simplify, assume:

$$
\begin{gathered}
S=S_{A}-S_{B} \\
\Delta h_{\text {act. }}=r_{1}-r_{2} \\
\Delta h_{o b s .}=r_{A}-r_{B}
\end{gathered}
$$

Then,

$$
\sum V^{2}=\sum\left(\Delta h_{o b s}-\left(\Delta h_{a c t}+S \theta\right)\right)^{2}
$$

Mathematically, this means that:

$$
\frac{\partial \sum V^{2}}{\partial \theta}=0
$$

By differentiation and simplification, the angle $(\theta)$ will have the form:

$$
\theta=\frac{\sum\left(\left[\left(r_{A_{i}}-r_{A_{j}}\right)-\left(r_{B_{i}}-r_{B_{j}}\right)\right] \cdot\left[\left(s_{A_{i}}-s_{A_{j}}\right)-\left(s_{B_{i}}-s_{B_{j}}\right)\right]\right)}{\sum\left[\left(s_{A_{i}}-s_{A_{j}}\right)-\left(s_{B_{i}}-s_{B_{j}}\right)\right]^{2}} . \rho^{/ /}
$$

Formula (3) is the second derived formula for calculating the collimation error (angle $\theta$ ) for leveling by using the second suggested modified observations technique. This technique can be applied for both digital and ordinary optical leveling.

\section{FIELd Work For Determining Angle $(\theta)$ For DiGITAL LEVEL}

For validating the suggested method of determining collimation error for digital leveling and the derived formula to calculate the angle $(\theta)$, field work must be carried out. The used precise digital level was Trimble DiNi and two bar code staves were used. The results can be drawn as following:

\section{A. Measurements with a digital level using first technique}

The test site was carried out in the laboratory using a specified digital level. Measurements were taken from six stations according to Fig. 1. Each level position, the horizontal distances and staff readings were obtained. The maximum distance between the two staves was $28.975 \mathrm{~m}$. The results and analysis of observations are shown in Tables 3 and 4.
TABLE 3: RESULTS OF OBSERVATIONS FOR DETERMINING ANGLE $(\theta)$ USING THE FIRST METHOD

\begin{tabular}{cccccc}
\hline $\begin{array}{c}\text { Digital } \\
\text { Level } \\
\text { Position }\end{array}$ & $\begin{array}{c}\text { Distance, } \\
\mathbf{S}_{\mathbf{A}}(\mathbf{m m})\end{array}$ & $\begin{array}{c}\text { Distance, } \\
\mathbf{S}_{\mathbf{B}}(\mathbf{m m})\end{array}$ & $\begin{array}{c}\text { Reading, } \\
\mathbf{r}_{\mathbf{A}}(\mathbf{m m})\end{array}$ & $\begin{array}{c}\text { Reading, } \\
\mathbf{r}_{\mathbf{B}}(\mathbf{m m})\end{array}$ & $\begin{array}{c}\Delta \mathbf{h}_{\text {obs }} \\
(\mathbf{m m})\end{array}$ \\
\hline 1 & 25349 & 3626 & 1413.05 & 1431.38 & -18.33 \\
2 & 21304 & 7509 & 1378.69 & 1396.58 & -17.89 \\
3 & 15753 & 13164 & 1403.55 & 1420.90 & -17.35 \\
4 & 12416 & 16488 & 1432.89 & 1450.29 & -17.40 \\
5 & 7943 & 20959 & 1397.54 & 1414.47 & -16.93 \\
6 & 3256 & 25667 & 1386.01 & 1402.34 & -16.33 \\
\hline
\end{tabular}

TABLE 4: CALCULATIONS FOR DETERMINING ANGLE $(\theta)$ USING THE FIRST PROPOSED OBSERVATIONS METHOD

\begin{tabular}{ccccccc}
\hline $\begin{array}{c}\text { Digital } \\
\text { Level } \\
\text { Position }\end{array}$ & $\begin{array}{c}\Delta \mathbf{h}_{\text {obs }} \\
(\mathbf{m m})\end{array}$ & $\begin{array}{c}\mathbf{S}_{\mathbf{B}} \\
(\mathbf{m m})\end{array}$ & $\begin{array}{c}\mathbf{S}_{\mathbf{A}} \\
(\mathbf{m m})\end{array}$ & $\mathbf{S}=\mathbf{S}_{\mathbf{A}}-\mathbf{S}_{\mathbf{B}}$ & $\mathbf{S . \Delta} \mathbf{h}_{\text {obs }}$ & $\mathbf{S}^{\mathbf{2}}$ \\
\hline 1 & -18.33 & 3626 & 25349 & 21723 & -398182.59 & 471888729 \\
2 & -17.89 & 7509 & 21304 & 13795 & -24679.55 & 190302025 \\
3 & -17.35 & 13164 & 15753 & 2589 & -44919.15 & 6702921 \\
4 & -17.40 & 16488 & 12416 & -4072 & 70852.8 & 16581184 \\
5 & -16.93 & 20959 & 7943 & -13016 & 220360.88 & 169416256 \\
6 & -16.33 & 25667 & 3256 & -22411 & 365971.63 & 502252921 \\
\hline
\end{tabular}

Then, angle $(\theta)$ can be calculated using the derived formula (eq. 5) as following:

$$
\theta^{\prime \prime}=\frac{-0.0262 \times 206265}{1357.144}=-3.97^{\prime \prime}
$$

By using this model, the value of angle $(\theta)$ equals - 3.97'", this means that the line of sight doesn't coincide with the optical axis of the digital level and is directed downward, which means that the line of collimation is not horizontal.

\section{B. Measurements with a digital level using second method}

The second test was measured in the laboratory using the same digital level and its bar code staff. Measurements taken from eight staff positions. Each staff position, the horizontal distances and staff readings were recorded. The distance between the two stations of level positions A and B was $27.334 \mathrm{~m}$. The results of the observations are shown in Table 5.

Then, angle $(\theta)$ can be calculated using the derived formula (eq. (11)) as following:

$$
\theta^{\prime \prime}=\frac{-0.04362 \times 206265}{293.01592}=-3.91^{\prime \prime}
$$

By using this model, the value of angle $(\theta)$ equals - 3.91//, this means that the line of sight doesn't coincide with the optical axis of the digital level and is directed downward, which means that the line of collimation is not horizontal. The resulting value of angle $(\theta)$ from the two methods is almost identical.

As shown in Table 7, when the amplitude of the oscillations is 40-55 microns, some readings on bar code staff often fail especially for long distances, but when the amplitude of the vibrations exceeds 60-80 microns, measurements are generally impossible.

To reduce the influence of the tripod-level vibration system on the digital level observations, vibration insulation linings 3-5 mm thick of felt or hard rubber were used, which were placed under the legs of the tripod. Their use can reduce the effects of vibration by approximately $30-40 \%$. 
TABLE 5: RESULTS OF OBSERVATIONS FOR DETERMINING ANGLE $(\theta)$ USING THE SECOND SUGGESTED MODIFIED METHOD

\begin{tabular}{|c|c|c|c|c|c|c|c|}
\hline \multirow[t]{2}{*}{ Bar code staff Position } & & \multicolumn{2}{|c|}{ Reading (mm) } & \multirow[b]{2}{*}{$\Delta \mathbf{h}_{\mathrm{i}, \mathrm{j}}=\left(\mathrm{r}_{\mathrm{A} 1}-\mathbf{r}_{\mathrm{A} 2}\right)-\left(\mathrm{r}_{\mathrm{B} 1}-\mathbf{r}_{\mathrm{B} 2}\right)$} & \multicolumn{2}{|c|}{ Distances } & \multirow[t]{2}{*}{$\Delta \mathbf{S}_{\mathrm{i}, \mathrm{j}}=\left(\mathbf{S}_{\mathrm{A} 1}-\mathbf{S}_{\mathrm{A} 2}\right)-\left(\mathbf{S}_{\mathrm{A} 1}-\mathbf{S}_{\mathrm{A} 2}\right)$} \\
\hline & & $\mathrm{r}_{\mathrm{A}}$ & $\mathrm{r}_{\mathrm{B}}$ & & $\mathrm{S}_{\mathrm{A}}$ & $S_{B}$ & \\
\hline 1 & \multirow{2}{*}{$1-2$} & 1450.24 & 1440.05 & & 1943 & 25391 & \multirow{2}{*}{5156} \\
\hline \multirow{2}{*}{2} & & & & -0.32 & & & \\
\hline & \multirow{2}{*}{$2-3$} & & & 2.46 & & & 7512 \\
\hline 3 & & 1465.45 & 1453.12 & & 8274 & 19054 & \multirow[b]{2}{*}{7208} \\
\hline \multirow{2}{*}{4} & $3-4$ & 145505 & 14465 & -2.93 & 11800 & 15170 & \\
\hline & \multirow{2}{*}{$4-5$} & נוצ. & 1440.53 & 0.40 & 11890 & $134 / 0$ & 7532 \\
\hline 5 & & 1434.12 & 1424.32 & & 15659 & 11699 & \multirow{2}{*}{6045} \\
\hline 6 & $5-6$ & 1247.06 & 1237.66 & 0.40 & 18670 & 8665 & \\
\hline & $6-7$ & & & 0.09 & & & 6990 \\
\hline 7 & \multirow{2}{*}{$7-8$} & 1500.02 & 1490.71 & 0 & 22166 & 5171 & \multirow{2}{*}{6519} \\
\hline 8 & & 1475.69 & 1466.80 & -0.42 & 25427 & 1913 & \\
\hline
\end{tabular}

\section{The EFFect Of VibRATIONS On Digital LeVEL OBSERVATIONS}

According to the standard specifications and certification for many geodetic instruments, the observations should be carried out in laboratory and field conditions under certain conditions: temperature, humidity and air pressure, wind speed and light exposure [3], [6].

The operation of these instruments should also be carried out in appropriate conditions, for example, at temperatures from $-35^{\circ} \mathrm{C}$ to $+40^{\circ} \mathrm{C}$, air humidity up to $90 \%$, wind speed up to $2 \mathrm{~m} / \mathrm{s}$ [3]. However, when performing measurements for an industrial or construction site, due to the operation of various mechanisms and equipment, vibration occurs on the surface of the earth or on the concrete base (floor in the workshops), on which a tripod with a digital level is mounted. Under these conditions, the frequency and amplitude of the oscillations are in the range, respectively, $1: 50 \mathrm{~Hz}$ and 10:40 microns. Sometimes the amplitude of the oscillations reaches 80-120 microns, and when driving piles at a construction site or during the operation of an overhead crane in the factory's workshop, it jumps to $1.0: 1.5 \mathrm{~mm}$. Since there are almost several sources of vibrations and oscillations of an industrial site, resonant phenomena also occur [9].

The influence of vibration on the system "tripod - digital level" leads to the fact that the compensator begins to make continuous angular oscillations relative to the plumb line. As a result of this, the line of sight also begins to make angular oscillations in the range of $20-180 / /$ at least [3].

Obviously, the effect of vibration will affect the accuracy of bar-code staff readings. So, for example, for high-precision levels with visual reading using an optical micrometer on an invariant rail, the error in measuring elevations due to fluctuations in strokes increases from $0.05-0.12 \mathrm{~mm}$ to 0.35 $-0.80 \mathrm{~mm}$. Sometimes, with a large amplitude of oscillations, leveling is generally difficult to perform $[3,9,11]$.

The influence of vibration on the system "tripod - level" also leads to a continuous violation of the equilibrium position of the compensator in a vertical circle. As a result, aiming the grid of threads on the target as well as during leveling becomes difficult and the angular transducers of the horizontal and vertical circles of code or cumulative types are disrupted.

Studies of the vibration effect on digital level observations were carried out in this paper for two observations cases; first in laboratory conditions and second during the performance of construction work in real conditions at District Power Station thorough determining the deformation of the turbine units foundations. The used digital level was Trimble DiNi and two bar code staves.

The first test was carried out in laboratory. To simulate vibration on tripod, an electric fan was fixed on the tripod leg. To create different vibration frequencies of the tripod, an eccentric with an additional mass was placed on the fan blades. The experiment was carried out in the daytime under natural light and a temperature of $240 \mathrm{C}$. The measurements were made at four staff stations at distances from level to bar code staff: $5.51 \mathrm{~m}, 9.93 \mathrm{~m}, 16.17 \mathrm{~m}, 20.67 \mathrm{~m}$. First, measurements were taken with the fan turned off at various distances to the staff. Then the fan was turned on, thereby transmitting the tripod, the vibration effect with a frequency of $\approx 10 \mathrm{~Hz}$, and measurements were made with the fan turned on. At the end of these measurements, an eccentric mass was attached to the fan blade (at various distances from the axis of rotation of the device) and the measurements were repeated.

In each series of measurements, 25 readings were made for the staff. For each distance, the vibration parameter was changed 5 times. To analyze the results, the standard deviation of measuring height elevations was calculated based on the measurements obtained. The results of the studies are shown in table (6).

From table (6), it is deduced that under the action of vibration there is a continuous measurement of the position of the sighting axis (its tilt up and down), then with an increase in the distance from the digital level to the bar code rod (staff), the change in reading will increase.

Research at District Power Station-2 was carried out in the immediate vicinity of the existing turbine units. The vibration amplitude specified in table (7) was selected by fixing the level in the bearing area with vibration parameters shown in the table. It should be noted that when performing research on the system "tripod level", the level was affected by the horizontal component of vibration. Since there is always a significant temperature difference when operating turbine units in the engine room, air turbulence significantly affects the position of the sight axis. 
TABLE 6: INVESTIGATION OF THE INFLUENCE OF VIBRATION OF THE "TRIPOD-LEVEL" SYSTEM ON THE ACCURACY OF MEASUREMENTS WITH A DIGITAL

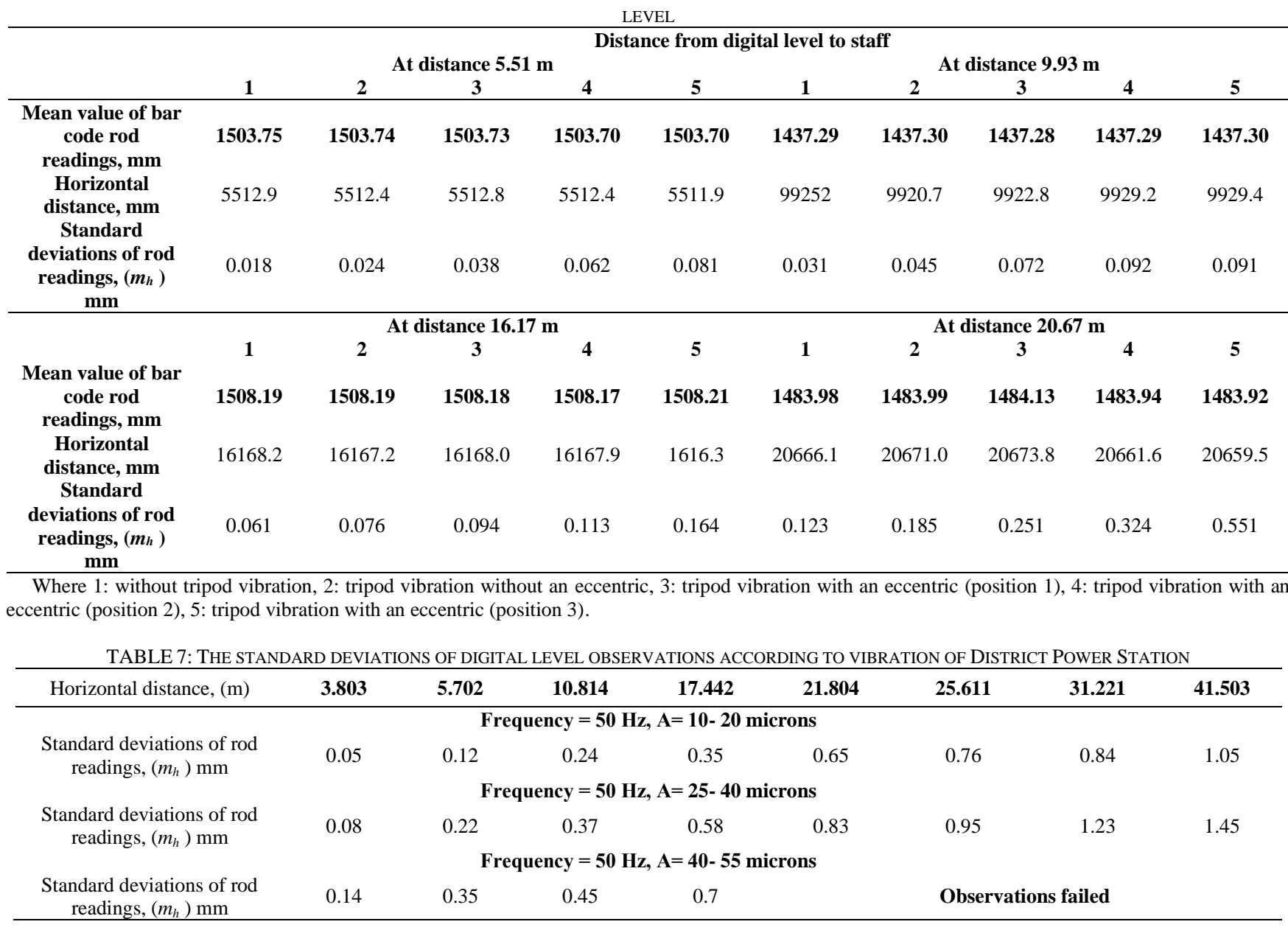

\section{CONCLUSION}

Depending on the results achieved, the following conclusion can be drawn:

1) Increasing the distance between the digital levels and bar-code staff will increase the errors of staff readings and horizontal distances, so when using digital level for engineering projects which require high accuracy, the distance between the level and the bar code staff should be small and not more than 30 meters.

2) The proposed methods for finding the collimation error are effective and vital and can be used as an alternative technique to the two pegs test because it is more accurate, especially when using least square estimation in calculating the value of the angle $(\theta)$. These techniques can be applied for digital and optical levels.

3) The quality and accuracy of measurements of modern electronic geodetic instruments may be affected by vibration and oscillations of engineering structures. When the amplitude of the vibration is great, the instrument will not work and failed. The effect of vibration on the measured distances depends on the magnitude of the distance itself. In this paper, with an oscillation amplitude of $10-20 \mu \mathrm{m}$ and a distance of $112 \mathrm{~m}$, the measurement error turned out to be 15 $20 \mathrm{~mm}$. With an oscillation amplitude of $40-45 \mu \mathrm{m}$, the values of this distance changed by $40-60 \mathrm{~mm}$. In addition, measurements often fail. The use of cushioning pads reduces the effect of vibration by $80-90 \%$.

4) To reduce the influence of the vibration and oscillations on the observations results of digital level, vibration insulation linings of felt or hard rubber can be used, which must be placed under the legs of the tripod. Their use can reduce the effects of vibration by $30-40 \%$.

\section{IMPORTANT NOTES}

The data are with the author and are available to anyone who needs it. This work has no funding.

\section{REFERENCES}

[1] Alba M., (2008) " Investigations about the accuracy of target measurement for deformation monitoring", The International Archives of the Photogrammetry, Remote Sensing and Spatial Information Sciences. Vol. XXXVII. Part B5. Beijing, p.p. 1053-1060.

[2] Ashraf A. A. Beshr, and Islam M. Abo Elnaga (2011) "Investigating the accuracy of digital levels and reflectorless total stations for purposes of geodetic engineering". Alexandria Engineering Journal Vol. 50, P. 399-405.

[3] Beshr A. A. (2010) "Development and innovation of technologies for deformation monitoring of engineering structures using highly accurate modern surveying techniques and instruments, Ph.D. thesis, Siberian State Academy of geodesy, Novosibirsk, Russia.

[4] Electronic Digital/Bar-Code Leveling User Manual - Version 2, Louisiana Spatial Reference Center, Louisiana State University. Baton Rouge. $75 \quad$ pp. Louisiana, (2005). http://www.ngs.noaa.gov/heightmod/Leveling/Manuals/Bar_Code_Pr ecision_Leveling_v2.pdf

[5] Elsheimy, N. (2001). "Adjustment of observations", Department of Geomatics Engineering, University of Calgary, Canada.

[6] Gairns C., " Development of semi-automated system for structural deformation monitoring using a reflectorless total station", M.sc. thesis, Department of Geodesy and Geomatics Engineering -University of New Brunswick, 118 p. (2008). 
[7] Gassner G., Ruland R., Dix B., " Investigations of digital levels at the SLAC vertical comparator" , IWAA2004, CERN, Geneva, (2004). http://iwaa2004.web.cern.ch/IWAA2004/subsite/PDF/20041007_TS1 1-2_Georg-Gassner.pdf

[8] Oriad, L.L. The effects of vibrations and Environmental forces International Society of Explosives Engineers, Cleveland, 1999

[9] Panos A.Psimoulis, Stathis C.Stiros (2007) "Measurement of deflections and of oscillation frequencies of engineering structures using Robotic Theodolites (RTS)" Journal "Engineering Structures" Vol. 29, Issue 12, Pages 3312-3324 https://doi.org/10.1016/j.engstruct.2007.09.006

[10] R. Ehigiator-Irughe and B. M. Mohammad Muhajir (2020) "Adjustment of Single and Double Braced Quadrilateral using Least Square Condition Equation" European Journal of Environment and Earth Sciences. www.ej-geo.org :10.24018/ejgeo.YEAR.Vol.Issue.ID

[11] Svinkin, M.R. (1999) "Prediction and calculation of construction vibrations. DFI 24th Annual Members' Conference, Decades of Technology - Advancing into the Future, 1999, 53-69.

[12] Wiss, J.F. (1981) "Construction vibrations: State-of-the-Art. American Society of Civil Engineers" ASCE Journal of Geotechnical Engineering, Vol. 107, No. GT2, 167-181.

[13] Woods R.D. (1997) "Dynamic effects of pile installations on adjacent structures. Synthesis Report, National Cooperative Highway Research Program NCHRP Synthesis 253, Washington, D.C., 1997.

[14] Wood, W.C and Theissen, J.R. (1982) "Variations in adjacent structures due to pile driving". Proceedings of the GEOPILE Conference, San Francisco, page 83-107.

[15] Woschitz, H. and Brunner, F.K. (2002) "System Calibration of Digital Levels-Experimental Results of Systematic Effects" INGEO2002, 2nd Conference of Engineering Surveying, Kopáčik A and Kyrinovič P (eds), Bratislava, November 2002: pp 165-172. 